\title{
The Effect of Potassium Citrate on Overactive Bladder Disease: A Cross-sectional Study
}

\author{
Murat Uçar ${ }^{1}$, Ali Akkoc ${ }^{1}$, Murat Topcuoglu' ${ }^{1}$, Sefa Alperen Ozturk ${ }^{2}$ and Murat Demir ${ }^{2}$ \\ ${ }^{1}$ Department of Urology, Alanya Alaaddin Keykubat University, Turkey \\ ${ }^{2}$ Department of Urology, Süleyman Demirel University, Turkey
}

\begin{abstract}
Objective: To show the effect of potassium citrate treatment on overactive bladder disease in patients with kidney stone and overactive bladder symptoms.

Study Design: Experimental study.

Place and Duration of Study: Department of Urology, Alanya Alaaddin Keykubat University and Department of Urology, Süleyman Demirel University, Turkey, from October 2019 to July 2020.

Methodology: Patients with an indication for starting potassium citrate therapy because of kidney stone, and patients with symptoms of overactive bladder disease were included in the study. At the beginning of the treatment, the overactive bladder-version 8 form was filled and potassium citrate 10 meq $2 \times 2$ dose was started to the patients. The effect of potassium citrate on the symptoms of overactive bladder disease was demonstrated by filling the overactive bladder-version 8 form after one month of treatment.

Results: A total of 82 people, 36 men and 46 women, participated in the study. Potassium citrate treatment caused a significant increase in urine $\mathrm{pH}$ levels $(\mathrm{p}<0.001)$. After potassium citrate treatment, there was a significant decrease in the score of the overactive bladder-version 8 form. $(p<0.001)$. A positive correlation was found between age and overactive bladder-version 8 score change $(p=0.004)$.

Conclusion: Potassium citrate can be used in the treatment of overactive bladder disease. The effect of potassium citrate treatment on ameliorating overactive bladder symptoms is more distinct in elderly patients.
\end{abstract}

Key Words: Renal stones, Potassium citrate, Overactive bladder.

How to cite this article: Uçar M, Akkoc A, Topcuoglu M, Ozturk SA, Demir M. The Effect of Potassium Citrate on Overactive Bladder Disease: A Cross-sectional Study. J Coll Physicians Surg Pak 2020; 30(12):1301-1305.

\section{INTRODUCTION}

Overactive bladder $(\mathrm{OAB})$ is a disease manifesting urgency as the main complaint, with or without incontinence, usually accompanied by pollakiuria manifesting and nocturia, and does not have any local pathological or metabolic reason to explain these symptoms. ${ }^{1} \mathrm{OAB}$ can occur idiopathically or due to pathologies originating from the central nervous system, peripheral nervous system or bladder. Bladder microbiome, bacterial infection, inflammation, urothelial permeability, psychological stress, anxiety, depression, some comorbidities cause excessive stimulation of peripheral afferent nerves. ${ }^{2}$ It ultimately causes urgency and pollakiuria, which are the main symptoms for $O A B$.

Correspondence to: Dr. Murat Uçar, Department of Urology, Alanya Alaaddin Keykubat University, Turkey

E-mail: ucarmurat07@gmail.com

Received: October 05, 2020; Revised: November 07, 2020;

Accepted: November 27, 2020

DOI: https://doi.org/10.29271/jcpsp.2020.12.1301
$O A B$ is a very common disease and its prevalence in the total population in the USA has been found to be $23.3 \%{ }^{3}$ It is mostly seen in older ages, which is an important public health problem. ${ }^{4}$ The initial treatment of $O A B$ is behavioural and pharmacological therapy. Pharmacologically, antimuscarinics and beta-3 agonists are frequently preferred medicines in the treatment of OAB. However, due to the high number of side effects, the rate of continuing treatment is very low. In one study, only a third of the patients continued the treatment in the first year of antimuscarinic treatment. ${ }^{5}$ In case of inefficacy or intolerance of the pharmacological treatment, intracavitary onabotulinum toxin injection, sacral neuromodulation, percutaneous tibial nerve stimulation, augmentation cystoplasty, and urinary diversion are other treatmentoptions that can be applied. ${ }^{6}$ None of these treatments are perfect, and each of them has advantages and disadvantages. $O A B$ is very difficult to treat because of the high side effects of standard treatments. Since there is no definitive treatment for $O A B$, there are new treatment searches. Forms such as $O A B$ - version (v) 8, OAB - (questionnare) q, OAB - q short form (SF) have been defined to evaluate the severity of symptoms in patients with OAB. ${ }^{7}$ (Appendix) OAB treatment efficiency can be evaluated with $O A B$ forms or urodynamic parameters. ${ }^{8}$ 
Potassium citrate is used in the treatment of kidney stones, especially uric acid stones, and in the prevention of stone recurrence. ${ }^{9}$ Potassium citrate reduces the formation of kidney stones or provides resolution of existing stones by decreasing urinary calcium excretion, increasing urinary citrate excretion and decreasing urine acidity. ${ }^{10,11}$ Potassium citrate and sodium bicarbonate are important pharmacological agents that increase urine $\mathrm{pH}^{12,13}$ Although the etiopathogenesis of $\mathrm{OAB}$ is not fully known, urinary alkalinisation can lead to decrease the symptoms of OAB. In a study conducted on patients diagnosed with $O A B$, it was observed that as urine alkalinisation increased, patients' complaints decreased. ${ }^{14}$ In the literature, potassium citrate has never been used in the treatment of OAB.

The aim of this study was to determine the improvement in $O A B$ symptoms after potassium citrate treatment in patients who started on potassium citrate therapy because of kidney stones and who also had OAB symptoms.

\section{METHODOLOGY}

This experimental study was conducted on patients who applied to Urology Outpatient Clinics in Alanya Alaaddin Keykubat University Training, Research Hospital and Süleyman Demirel University Medical Faculty Hospital between October 2019 and July 2020. Complete urine analysis and blood urea, creatinine, sodium, potassium and chlorine levels were studied for all patients included in the study, before potassium citrate treatment. Urine culture was sent from patients with suspected urinary tract infection, and if it was positive as a result of the culture, it was accepted that they had active urinary tract infection. All patients were started potassium citrate at a dose of 10 $\mathrm{mEq} 2 \times 2$ per day. The patients were informed that this medicine was started because of kidney stones, and no information was given about its effect on lower urinary tract functions. Before starting the treatment, a form was filled in for the patients to be included in the study.

The demographic information of the patient, his / her background information, the dose of potassium citrate started, the results of the complete urine test, and the results of the Turkish version of OAB-v8 were noted on this form. ${ }^{15}$ After one month of starting potassium citrate, the same OAB-v8 form was filled again and urine analysis, blood urea, creatinine, sodium, potassium and chlorine levels were examined. During this period, questions were asked about whether a new medicine was started or whether there was an active urinary system infection. According to the OAB-v8 form score, the patients were divided into two groups with a score of $\leq 11$ and $>11$. We accepted this score as threshold value for $O A B$ disease diagnosis due to a study conducted in Turkey, which is determined the threshold value as 11 in OAB-v8 form. ${ }^{15}$

The criteria used for inclusion of patients to the study were patients having kidney stone, urine $\mathrm{pH} \leq 6.5$, and an indication for starting potassium citrate therapy; who also had $O A B$ disease symptoms. The indication for starting potassium citrate treatment was determined as patients with kidney stones or a history and urine $\mathrm{pH}$ level of 6.5 or lower. Urine analysis for 24hour could not be performed from the all patients. The exclusion criteria were: patients who have been operated in the last month with the diagnosis of kidney stones, patients with stones causing obstruction in the ureter or urinary collecting system, patients with active urinary tract infections, hyperkalemia, patients receiving other treatment for OAB disease, and patients with bladder irritation or disease that can lead to a neurogenic bladder. Diabetes mellitus, medulla spinalis disease or trauma history of medulla spinalis, Alzheimer, Parkinsonism, and multiple sclerosis were considered as diseases that could cause neurogenic bladder.

Statistical measurements were made with SPSS version 22 package programme (SPSS Inc., Chicago, IL). Descriptive statistics, i.e. mean, S.D, median and (IQR: Q1-Q3) about demographic characteristics and backgrounds of the patients were given. Whether the data was normally distributed was determined by Kolmogrov-Smirnov test. Independent sample t-test was used to compare two independent groups. Paired samples t-test was used to compare the pre-treatment and post-treatment, if the data met the parametric test assumptions; and Wilcoxon test, if parametric test assumptions were not provided. In patients whose scores were grouped as $\leq 11$ and $>11$ according to the OAB-v8 form score, pre-treatment and post-treatment efficacy were examined using the Mc Nemar test. The relationship between the two variables was examined using the Pearson correlation or Spearman correlation. The $p$ values $<0.05$ were regarded as statistically significant for all analysis. With a value of $\mathrm{R}$ between $0.21-0.50$, the correlation degree was interpreted as modest degree. ${ }^{16}$

All procedures performed in studies involving human participants were in accordance with the ethical standards of the Institutional Research Committee and with the 1964 Helsinki Declaration and its later amendments or comparable ethical standards. This study was approved by Alanya Alaaddin Keykubat University Medical Ethics Committee, Turkey (10354421 2019/4). Informed consents were obtained from all individual participants included in the study.

\section{RESULTS}

At the beginning of the study, 98 patients were included to the study. There were 24 people suspected of urinary tract infection according to clinical and laboratory findings before treatment. Urine cultures were taken from all of these patient. Sixteen patients had positive urine culture and they were excluded from the study. A total of 82 people, 36 (43.9\%) men and 46 (56.1\%) women, participated in the study. The mean (SD) age of the patients was found to be as $50.48 \pm 11.03$ years. No significant change was observed in the blood creatinine, sodium, potassium and calcium values in the control performed one month later, compared to the beginning of the treatment (Table I). During the treatment process, $25(30.5 \%)$ patients werestarted on other medicines simultaneously. These medicines were diclofenac, trometamol, hyoscine-N-butylbromide, paracetamol, ibuprofen, alverine citrate + simethicone. 
Table I: Comparison of data before and after potassium citrate treatment.

\begin{tabular}{|c|c|c|c|}
\hline Parameters & Pretreatment & Posttreatment & p-value \\
\hline OAB-v8 score mean (SD) & $27.07(3.41)$ & $14.32(3.21)$ & $<0.001$ \\
\hline Urine $\mathrm{pH}$, median (Q1-Q3) & $6.0(5.5-6.0)$ & $6.5(6.5-7.0)$ & $<0.001$ \\
\hline Uriner density mean (SD) & $1015.90(4.91)$ & $1015.73(4.14)$ & 0.750 \\
\hline Leukocyte in urine median (Q1-Q3) & $0(0-3)$ & $0(0-0.25)$ & $<0.001$ \\
\hline Erythrocyte in urine, median (Q1-Q3) & $0.50(0-5.25)$ & $0(0-0)$ & $<0.001$ \\
\hline Creatinin, median (Q1-Q3) & $0.86(0.51-1.61)$ & $0.87(0.55-1.40)$ & 0.350 \\
\hline Sodium, median (Q1-Q3) & $140(137.75-141)$ & $139(138-140)$ & 0.494 \\
\hline Potassium, median (Q1-Q3) & $4.41(4.26-4.76)$ & $4.58(4.29-4.78)$ & 0.037 \\
\hline
\end{tabular}

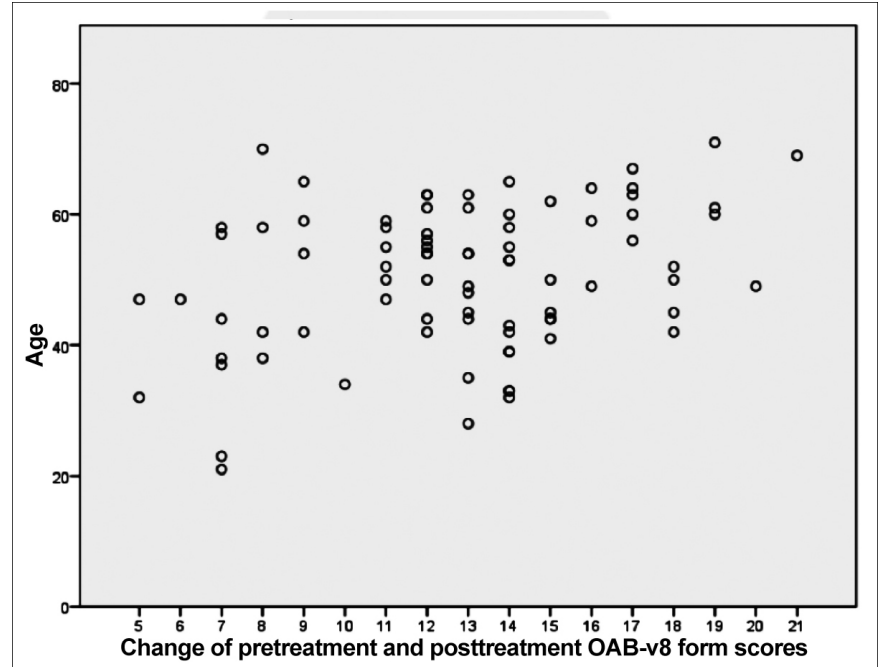

Figure 1: The relationship between age and change of OAB-v8 form scores after potassium citrate treatment.

There was no difference between men (12.42 \pm 3.81$)$ and women $(13.02 \pm 3.59)$ in OAB-v8 score decrease $(p=0.463)$. Both genders were equally or closely affected by potassium citrate treatment in terms of ameliorating in $O A B$ symptom.

A positive correlation was found between age and OAB-v8 score change $(r=0.317, p=0.004)$. As the age progresses, the decrease in OAB-v8 scores in patients on potassium citrate treatment is more distinct. Potassium citrate is more effective in reducing symptoms associated with $O A B$ in elderly patients than in younger patients (Figure 1). The differences between pre-treatment and post-treatment OAB-v8 form scores were calculated. After potassium citrate treatment, there was a significant decrease in the score of the OAB-v8 form, ( $p$ $<0.001$, Table I). When we grouped the patients as scores $\leq 11$ and $>11$ according to the OAB-v8 form scores, the scores of all patients were $>11$ before treatment. After treatment, $14(17.1 \%)$ of these patients scored $\leq 11$ and were excluded from the $O A B$ definition. The difference was found to be statistically significant $(p<0.001)$. It was observed that the median of urine $\mathrm{pH}$ increased after the treatment. Potassium citrate treatment caused a significant increase in urine $\mathrm{pH}$ levels $(\mathrm{p}<0.001)$. However, the relationship between the amount of change in OAB-v8 scores and the amount of $\mathrm{pH}$ change was evaluated; and it was concluded that there was no significant relationship between them $(r=0.136, p=0.224)$.

\section{DISCUSSION}

All patients had $O A B$ disease before treatment, according to the definition of Tarcan et al. The frequency of OAB differs from society to society, but it is generally more common in women. ${ }^{17}$ In a large-scale prevalence study conducted in China, the prevalence of $O A B$ in women and men was found to be quite close to each other. ${ }^{18}$ In this study, the number of women who participated in the study, that is, diagnosed with $O A B$, was more consistent with majority of the literature. Both genders responded equally or closely to potassium citrate treatment in terms of ameliorating in $\mathrm{OAB}$ symptoms.

The incidence of $O A B$ increases as age and comorbidities increase.$^{19}$ In a study conducted in the USA investigating the burden of OAB patients on the economy, an average of 3003 dollars per patient per month is spent for the treatment of $O A B$ patients. ${ }^{20}$ Considering that $O A B$ is a chronic disease, the economic burden of these patients is quite high. In our study, we observed that the rate of benefit from potassium citrate treatment increased as the age got older. Potassium citrate is a more economical agent that can be used in the treatment of $O A B$ especially in elderly patients because it is a cheaper treatment.

In one study, urine $\mathrm{pH}$ levels were found low in most of $O A B$ patients. ${ }^{21}$ In the same study, OAB-v8 scores were found higher in patients with acidic urine than those with alkaline urine. From this, it can be concluded that reducing urinary acidity will decrease $O A B$ symptoms. In this study, in line with this information, a significant difference was observed between pre-treatment $O A B$-v8 scores and post-treatment OAB-v8 scores. Potassium citrate treatment reduced the symptoms of patients diagnosed with $O A B$ and caused a decrease in OAB-v8 scores. In addition, according to the Turkish-validated form of $O A B-v 8$, all patients were diagnosed as $O A B$ before potassium citrate treatment, and it was observed that $17 \%$ of these patients were not diagnosed as $O A B$ after potassium citrate treatment. ${ }^{15}$ Potassium citrate therapy is an effective drug that can be used in the treatment of patients with $O A B$.

Urine $\mathrm{pH}$ value can vary depending on diet, diseases and medicines used. Sönmez et al. used sodium bicarbonate for urine alkalinisation. ${ }^{22}$ 


\begin{tabular}{|c|c|c|c|c|c|c|}
\hline How bothered have you been by & Not at all & A little bit & Somewhat & Quite a bit & A great deal & $\begin{array}{c}\text { A very great } \\
\text { deal }\end{array}$ \\
\hline $\begin{array}{l}\text { 1. Frequent urination during } \\
\text { the daytime hours? }\end{array}$ & 0 & 1 & 2 & 3 & 4 & 5 \\
\hline 2. An uncomfortable urge to urinate? & 0 & 1 & 2 & 3 & 4 & 5 \\
\hline $\begin{array}{l}\text { 3. A sudden urge to urinate with little or no } \\
\text { warning? }\end{array}$ & 0 & 1 & 2 & 3 & 4 & 5 \\
\hline 4. Accidental loss of small amounts of urine? & 0 & 1 & 2 & 3 & 4 & 5 \\
\hline 5. Night time urination? & 0 & 1 & 2 & 3 & 4 & 5 \\
\hline $\begin{array}{l}\text { 6. Waking up at night because you had to } \\
\text { urinate? }\end{array}$ & 0 & 1 & 2 & 3 & 4 & 5 \\
\hline 7. An uncontrollable urge to urinate? & 0 & 1 & 2 & 3 & 4 & 5 \\
\hline $\begin{array}{l}\text { 8. Urine loss associated with a strong desire } \\
\text { to urinate? }\end{array}$ & 0 & 1 & 2 & 3 & 4 & 5 \\
\hline
\end{tabular}

After 4 weeks of sodium bicarbonate treatment, while urine $\mathrm{pH}$ increased from 5.31 to 7.2 on average, there was no significant change in blood $\mathrm{pH}$ values. In our study, a significant increase was observed in urine $\mathrm{pH}$ levels after potassium citrate treatment. However, there was no significant relationship between the amount of change in urine $\mathrm{pH}$ and the amount of change in the OAB-v8 score. Too much urine $\mathrm{pH}$ change does not mean that there will be more improvement in the patient's complaints and a greater decrease in OAB-v8 scores.

Potassium citrate can also cause changes in blood electrolyte values, especially potassium levels, as well as changes in urine parameters. In a study, it was observed that there was no significant change in blood calcium levels after potassium citrate treatment. ${ }^{23}$ In another study, it was found that there was no significant change in the blood creatinine, sodium, potassium and calcium levels in which potassium citrate treatment was initiated and after 3 months. ${ }^{24}$ In this study, no significant change was observed in these blood values after one month of treatment in accordance with the literature. Nevertheless, blood sodium, potassium, calcium and creatinine levels should be checked at regular intervals during potassium citrate treatment. Blood electrolyte levels should be closely monitored, especially in elderly patients and patients with comorbidities.

There are some limitations in our study. It was assumed that the agents which the patients started with other indications did not affect the bladder or voiding functions. Although these agents are not related to the bladder, they can affect urine $\mathrm{pH}$ and bladder functions by mechanisms we do not know. Another limitation is any fluid and dietary advice was provided to patients that might affect urinary $\mathrm{pH}$. Each patient was free on his/her own fluid consumption and diet.

This study is the first study in the literature on the effect of potassium citrate on reducing OAB symptoms. Patients with a diagnosis of $O A B$; and particularly those, suffering from the side effects of anticholinergic treatments may benefit from potassium citrate therapy. The effect of potassium citrate treatment on ameliorating $O A B$ symptoms in elderly patients is more distinct. Larger randomised prospective placebo controlled studies are needed for clear data on treatment efficacy, safety, and patient compliance.

\section{CONCLUSION}

$O A B$ is a chronic disease that affects a large part of the society. The treatment is lengthy and its cost is very high. Increasing the urine $\mathrm{pH}$ value with potassium citrate may be a part of the treatment of this disease.

\section{ETHICAL APPROVAL:}

All procedures performed in this study involving human participants were in accordance with the ethical standards of The Institutional Research Committee and with the 1964 Helsinki Declaration, and its later amendments or comparable ethical standards. This study was approved by Alanya Alaaddin Keykubat University Medical Ethics Committee, (10354421-2019/4) Turkey.

\section{PATIENTS' CONSENT:}

Informed consents were obtained from all individual participants included in the study.

\section{CONFLICT OF INTEREST:}

Authors declared no conflict of interest.

\section{AUTHORS' CONTRIBUTION:}

MU: Design of the work, analysis, drafting the work, revising it critically, final approval of the version to be published.

AA: Substantial contributions to the conception, revising it critically.

MT: Analysis, revising it critically, final approval of the version to be published.

SAO: Design of the work, revising it critically.

MD: Acquisition, drafting the work, integrity of any part of the work are appropriately investigated and resolved.

\section{REFERENCES}

1. Deeks ED. Mirabegron: A review in overactive bladder syndrome. Drugs 2018; 78(8):833-44. doi: 10.1007/ s40265-018-0924-4.

2. Grundy L, Caldwell A, Brierley SM. Mechanisms underlying overactive bladder and interstitial cystitis/painful bladder 
syndrome. Frontiers Neuroscience 2018; 12:931. doi: 10.3389/fnins.2018.00931.

3. Reynolds WS, Fowke J, Dmochowski R. The burden of overactive bladder on us public health. Curr Bladder dysfunc Rep 2016; 11(1):8-13. doi: 10.1007/s11884- 016-0344-9.

4. Coyne KS, Sexton CC, Bell JA, Thompson CL, Dmochowski R, Bavendam $\mathrm{T}$, et al. The prevalence of lower urinary tract symptoms (LUTS) and overactive bladder (OAB) by racial/ethnic group and age: Results from OAB-POLL. Neurourol Urodyns 2013; 32(3):230-7. doi: 10.1002/ nau.22295.

5. Sexton CC, Notte SM, Maroulis C, Dmochowski RR, Cardozo $\mathrm{L}$, Subramanian D, et al. Persistence and adherence in the treatment of overactive bladder syndrome with anticholinergic therapy: A systematic review of the literature. Int J Clini Prac 2011; 65(5):567-85. doi: 10.1111/j.17421241.2010.02626.x.

6. Marcelissen T, Cornu JN, Antunes-Lopes T, Geavlete B, Delongchamps NB, Rashid T, et al. Management of idiopathic overactive bladder syndrome: What is the optimal strategy after failure of conservative treatment? European Urology Focus 2018; 4(5):760-7. doi: 10.1016/ j.euf.2018. 05.004 .

7. Acquadro C, Kopp Z, Coyne KS, Corcos J, Tubaro A, Choo MS, et al. Translating overactive bladder questionnaires in 14 languages. Urology 2006; 67(3):536-40. doi: 10.1016/ j.urology.2005.09.035.

8. Wei C, Gao J, Kou L, Liu X, Lin T, He D. Can urodynamic findings of overactive bladder determine the treatment effect of urotherapy in children? JCPSP 2020; 30(1):41-5. doi: 10.29271/jcpsp.2020.01.41.

9. Song L, Maalouf NM. Nephrolithiasis. In: Feingold KR, Anawalt B, Boyce A, Chrousos G, de Herder WW, Dungan K, et al., editors. Endotext. South Dartmouth (MA): MDText.com, Inc.Copyright (c) 2000-2020, MDText.com, Inc. 2000.

10. Song Y, Hernandez N, Shoag J, Goldfarb DS, Eisner BH. Potassium citrate decreases urine calcium excretion in patients with hypocitraturic calcium oxalate nephrolithiasis. Urolithiasis 2016; 44(2):145-8. doi: 10.1007/s00240015-0819-8.

11. Alenezi NA, Zanaty F, Hodhod A, El-Gharabawy M, El-Sherif E, Badawy $A$, et al. The safety of ureteral stenting with the use of potassium citrate for management of renal uric acid stones. Urology annals 2020; 12(1):37-41. doi: 10.4103/ UA.UA_60_19.

12. Shen J, Zhang $X$. Potassium citrate is better in reducing salt and increasing urine $\mathrm{pH}$ than oral intake of lemonade: $\mathrm{A}$ cross-over study. Med Sci Monitor 2018; 24:1924-9. doi: 10.12659/msm.909319.
13. Sönmez MG, Ecer G, Atici A, Özkent MS, İyisoy MS, Öztürk A. Comparison of oral sodium bicarbonate and solifenacin treatment in female overactive bladder patients with acidic urine pH. Female Pelvic Med Reconstr Surg 2018; 26(10):649-53. doi: 10.1097/SPV.0000000000000642.

14. Ueda $T$, Yoshida $T$, Tanoue $H$, Ito $M$, Tamaki $M$, Ito $Y$, et al. Urine alkalization improves the problems of pain and sleep in hypersensitive bladder syndrome. Int J Urol 2014; 21(5):512-7. doi: 10.1111/iju.12324.

15. Tarcan T, Mangır N, Özgür MÖ, Akbal C. OAB-V8 Aşırı aktif mesane sorgulama formu validasyon çalışması. Üroloji Bülteni 2012; 21(21):113-6.

16. Muijs D. Doing quantitative research in education with SPSS. Sage 2010; 139.

17. Plata M, Bravo-Balado A. Prevalence of lower urinary tract symptoms and overactive bladder in men and women over 18 years old: The colombian overactive bladder and lower urinary tract symptoms (COBaLT) study. Neurourol Urodyn 2019; 38(1):200-7. doi: 10.1002/nau.23828.

18. Wang $Y, X u K$, Hu H, Zhang $X$, Wang $X, N a Y$, et al. Prevalence, risk factors, and impact on health related quality of life of overactive bladder in China. Neurourol Urodyn 2011; 30(8):1448-55. doi: 10.1002/nau.21072.

19. Robinson D, Åkervall S, Wagg A, Chapple C, Milsom I, Gyhagen $M$. Prevalence and predictors of overactive bladder in nonpregnant nulliparous women below 65 years of age. Int Urogyn 2018; 29(4):531-7. doi: 10.1007/ s00192017-3435-z.

20. Gray S, Fowler R, Juneau P, Gooch K. Neurourology and urodynamics.

21. Demirbas A, Sarici H, Kilinc MF, Telli O, Ozgur BC, Doluoglu $O G$, et al. The relationship between acidic urinary ph and overactive bladder; alkalization of urine improves the symptoms of overactive bladder. Urologia Internationalis 2015; 95(2):223-6. doi: 10.1159/000375322.

22. Sönmez MG, Göğer YE, Ecer G, Atıcı A, Özkent MS, Öztürk A. Effects of urine alkalinization with sodium bicarbonate orally on lower urinary tract symptoms in female patients: a pilot study. Intern Urogynecol J 2018; 29(7):1029-33. doi: 10.1007/s00192-017-3492-3.

23. Marangella $M$, Di Stefano $M$, Casalis $S$, Berutti $S, D^{\prime}$ Amelio $P$, Isaia GC. Effects of potassium citrate supplementation on bone metabolism. Calcified Tissue Internat 2004; 74(4): 330-5. doi: 10.1007/s00223-003-0091-8

24. Granchi D, Caudarella R, Ripamonti C, Spinnato P, Bazzocchi A, Massa A, et al. Potassium citrate supplementation decreases the biochemical markers of bone loss in a group of osteopenic women: The results of a randomised, double-blind, placebo-controlled pilot study. Nutrients 2018; 10(9) :1293. doi: 10.3390/nu10091293. 